\title{
Mid-trimester blood glucose levels and pregnancy outcomes in large babies
}

\author{
Fernando T R $\mathbf{N}^{1}$
}

\begin{abstract}
Introduction: Large for gestational age at term could be following maternal diabetes and it affects neonatal mortality and morbidity. The aims of this study were to assess, firstly the mid-trimester blood glucose levels and secondly to assess the pregnancy outcomes of the macrosomic babies.
\end{abstract}

Methods: This was a retrospective descriptive study conducted at labour room $\mathrm{C}$ of Castle Street Hospital for Women during 15th May 2012 to 25th October 2012. Pregnancy records, delivery notes and admission notes to the neonatal care units were retrieved in order to find the mid-trimester blood glucose levels, mode of delivery, neonatal morbidity and mortality, stillbirth rate and occurrence of shoulder dystocia.

Results: There were 149 with a BW of $\geq 3.5 \mathrm{~kg}$ out of 1363 total deliveries. Rate of macrosomia was $11 \%$. There were 133 women with documented ANBG. Majority (90\%) of the women with a BW of $\geq 3.5 \mathrm{Kg}$ were classified as non-diabetes. Out of the mothers who were diagnosed as diabetes (15 cases) in pregnancy, 13 were gestational diabetes (GDM) while two were type 2 diabetes. Majority had a vaginal delivery $(n-105,70.5 \%)$. Out of these, six (4\%) were instrumental deliveries (4-forcep, 2 vacuum deliveries). There was one stillbirth and zero neonatal deaths reported in this study group. There were three $(2 \%)$ third degree perineal tears, two following NVD and one following forceps delivery.

Conclusions: Majority of mothers with babies with birthweight $>3.5 \mathrm{~kg}$ did not have altered blood glucose levels. Further prospective studies are needed to define the association of adverse perinatal outcomes and macrosomia.

Key words: macrosomia, polyhydramnios, stillbirth, diabetes mellitus, shoulder dystocia

\section{Introduction}

Over the last two to three decades there has been a $15-25 \%$ increase, in the number of women giving birth to large infants in many countries ${ }^{1}$. Large birth weight affects neonatal mortality and morbidity ${ }^{1}$. Rates of shoulder dystocia and caesarean birth rise substantially with larger birth weights ${ }^{2}$. The

${ }^{1}$ Department of Obstetrics and Gynaecology, Faculty of Medicine, Rajarata University, Sri Lanka.

Correspondence: T R N Fernando

E-mail: romaniefernando@yahoo.com

Competing interests: None. incidence of shoulder dystocia in all deliveries is approximately $1 \%$ but the incidence increases with macrosomia (birth weight $\geq 90$ th percentile) $)^{2}$. Sri Lankan standard for macrosomia at term is $3500 \mathrm{~g}$ or more ${ }^{3}$. Maternal characteristics such as weight, height, parity and ethnicity need to be adjusted to establish an appropriate standard for normal birth weight for gestation ${ }^{4}$.

Many observers assume that the trend for large birth weight is rising in the urban areas of Sri Lanka. However we lack published data on large birth weight and the outcomes of neonates. The aims of this study were to assess, firstly the midtrimester blood glucose levels and secondly to assess the pregnancy outcomes of the macrosomic babies.

\section{Methods}

This was a retrospective descriptive study conducted at labour room C of Castle Street Hospital for women during 15th May 2012 to 25th October 2012. Pregnancy records, delivery notes and admission notes to the neonatal care units were retrieved in order to find the mid-trimester blood glucose levels, mode of delivery, neonatal morbidity and mortality, stillbirth rate and occurrence of shoulder dystocia.

\section{Results}

There were 1363 deliveries reported during the study period. There were 149 (11\%) born with BW of $\geq 3500 \mathrm{~g}$, included for the analysis. Of the study group, $52(35 \%)$ women were primiparous and $97(65 \%)$ were multiparous. The average age of the mother, mean gestational age at delivery and mean BW of the study sample were; 29.6 years $(\mathrm{SD}=4.74), 39.4$ weeks $(\mathrm{SD}=1.94)$ and $3.72 \mathrm{Kg}(\mathrm{SD}=1.07)$ respectively.

There were 133 women who had documentation of the antenatal blood glucose (ANBG) results in their hospital medical records. Documented ANBG were; two hours post prandial blood sugar in 104 women, $75 \mathrm{~g}$ oral glucose tolerance test (OGTT) in 84 women and $50 \mathrm{~g}$ oral glucose challenge test in 12 women. Majority $(90 \%)$ of the women with a BW of $\geq 3.5 \mathrm{~K} \mathrm{~g}$ were classified as nondiabetes. Out of whom diagnosed as diabetes ( 15 cases) in pregnancy, 13 were gestational diabetes (GDM) while two were type 2 diabetes. Out of the 15 
diabetes women, five had taken insulin treatment while the other 10 were on diet control only. Majority had a vaginal delivery (n-105, 70.5\%). Out of these, six $(4 \%)$ were instrumental deliveries (4-forcep, 2 vacuum deliveries). One instrumental delivery was complicated with shoulder dystocia, without any adverse neonatal sequelae. There were three $(2 \%)$ third degree perineal tears, two following NVD and one following forceps delivery. There were $44(29.5 \%)$ caesarean sections (LSCS), of which 25 were emergency LSCS.

There was one stillbirth and six neonates were admitted to neonatal unit for observation, five for hypoglycaemia and one for shoulder dystocia. Majority (94\%) of the neonates were normal at birth and were without any immediate neonatal complications. All neonates were discharged from the hospital within 72 hours after delivery.

\section{Discussion}

This study demonstrated that majority of pregnancies with macrosomic babies at term did not have altered glycaemic status during the antenatal period. Given the $10 \%$ occurrence of diabetes status in large for gestational age pregnancies, screening based on clinical or ultrasound evidence of large for gestational age pregnancies is still justified. However, it is important to recognise that none of the commonly using ultrasound estimated fetal formulae do not accurately predict the actual fetal weight in Sri Lankan fetuses after 34 weeks ${ }^{5}$. Literature reveals that about $70 \%$ of large birth weights are due to prolong pregnancy, constitutional or genetic factors and macrosomia occurring due to hyperglycaemia in diabetes women is only $30 \%{ }^{6}$. Our study found that only $10 \%$ of women with large birth weights were diagnosed as diabetes in pregnancy.

It has been reported that macrosomic babies carry higher risk of caesarean and operative vaginal deliveries ${ }^{6}$. However, caesarean section rate for macrosomic babies in our study was not too high compared to other published studies in Sri Lanka ${ }^{7}$. Main limitations of this study were the sample size and the retrospective nature. Further prospective studies will be needed to define the association of adverse perinatal outcomes and macrosomia.

\section{Acknowledgements}

I acknowledge the assistance given by Dr. Y A G Perera, Consultant Obstetrician and Gynaecologist, Dr. J R Ranasinghe, Senior House Officer, Castle Street Hospital for Women, Colombo and Dr. A N Wijenayake, Senior Lecturer, Department of Industrial Management, Faculty of Science, University of Kelaniya, Sri Lanka.

\section{REFERENCES}

1. Aye SS, Miller V, Saxena S, Farhan M. Management of large-for-gestational-age pregnancy in non-diabetic women. The Obstetrician and Gynaecologist 2010; 12 : 250-6.

2. Lerner $\mathrm{H}$. Shoulder dystocia, facts Evidence and conclusions. http:// www.shoulderdystociainfo.com/ shoulder_dystocia.htm

3. Shanmugaraja Y, Kumarasiri SG, Wahalawatte SL, Wanigasekara RV, Begam P, Jayasinghe PK, Padeniya T, Dias T. Sri Lankan fetal/ birthweight charts: validation of global reference for fetal weight and birthweight percentiles. Ceylon Med J. 2013; 58(2): 62-5.

4. De Jong CL, Gardosi J, Dekker GA, Colenbrander GJ, Van Geijn HP. Application of a customised birth weight standard in the assessment of perinatal outcome in a highrisk population. British Journal of Obstetrics and Gynaecology 1997; 105: 531-5.

5. Kumarasiri S, Wanigasekara R, Wahalawatta L, Jayasinghe L, Padeniya T, Dias T. Accuracy of ultrasound estimated fetal weight formulae to predict actual birthweight after 34 weeks: prospective validation study. Ceylon Med J. 2013; 58(3): 116-21.

6. Stotland NE, Caughey AB, Breed EM, Escobar GJ. Risk factors and obstetric complications associated with macrosomia. International Journal of Gynaecology and Obstetrics 2004; 87: 220-6.

7. Goonewardene M, Kumara MA, Jathun Arachchi DR, Vithanage R, Wijeweera R. The rising trend in caesarean section rates: should we and can we reduce it? Sri Lanka Journal of Obstetrics and Gynaecology 2012; 34: 11-8. 